\title{
Measuring professional satisfaction and nursing workload among nursing staff at a Greek Coronary Care Unit
}

\author{
Avaliação da satisfação profissional e carga laboral das equipes de \\ enfermagem nas Unidades de Cuidados Coronarianos Gregas \\ Evaluación de la satisfacción profesional y de la carga laboral del personal \\ de enfermería en las Unidades Griegas de Cuidados Coronarios
}

Maria Gouzou${ }^{1}$, Maria Karanikola², Chryssoula Lemonidou³, Elizabeth Papathanassoglou², Margarita Giannakopoulou ${ }^{3}$

${ }^{1}$ Kalamata's General Hospital, Kalamata, Greece.

${ }^{2}$ Cyprus University of Technology, School of Nursing, Limassol, Cyprus.

${ }^{3}$ National and Kapodistrian University of Athens, Faculty of Nursing, Athens, Greece.

\section{ABSTRACT}

Objective: To explore potential associations between nursing workload and professional satisfaction among nursing personnel (NP) in Greek Coronary Care Units (CCUs). Method: A cross-sectional study was performed involving 66 members of the NP employed in 6 randomly selected Greek CCUs. Job satisfaction was assessed by the IWS and nursing workload by NAS, CNIS and TISS-28. Results: The response rate was $77.6 \%$. The reliability of the IWS was $\alpha=0.78$ and the mean score $10.7( \pm 2.1$, scale range: $0.5-39.7)$. The most highly valued component of satisfaction was "Pay", followed by "Task requirements", "Interaction", "Professional status", "Organizational policies" and "Autonomy". NAS, CNIS and TISS-28 were negatively correlated $(p \leq 0.04)$ with the following work components: "Autonomy", "Professional status", "Interaction" and "Task requirements". Night shift work independently predicted the score of IWS. Conclusion: The findings show low levels of job satisfaction, which are related with nursing workload and influenced by rotating shifts.

\section{DESCRIPTORS}

Nursing,Team; Coronary Care Unit; Workload;Job Satisfaction; Shift Work; Professional Autonomy.
Correspondence Addressed to:

Dr. Margarita Giannakopoulou

National \& Kapodistrian University of Athens, Faculty of Nursing

123, Papadiamantopoulou str, 11527 Athens, Greece mgiannak@nurs.uoa.gr
Received: 04/10/2015

Approved: 07/14/2015 


\section{INTRODUCTION}

Professional satisfaction is considered as "the affective response resulting from an evaluation of the work situation"(1). Studies on hospital nurses have revealed that professional satisfaction is a factor related to work effectiveness, productivity, absenteeism, quitting the job, turnover, patient safety and quality of care $^{(2-3)}$. There have been several attempts to measure professional satisfaction of nurses in Intensive Care Unit (ICU) settings ${ }^{(4-5)}$, whilst moderate job satisfaction has been consistently reported among them ${ }^{(6-8)}$.

In the last decade, there has been a growing interest in the measurement of nursing workload at ICUs. Nursing workload monitoring is currently oriented towards the improvement of the quality of care. Although the international literature has revealed the impact of nursing workload on patient safety, outcomes and effectiveness of health care systems ${ }^{(9-12)}$, only a limited number of research studies have explored the impact of nursing workload on ICU nurses' work satisfaction and quality of working life $^{(13)}$. Furthermore, research reports exploring nurses' work satisfaction or nursing workload in Coronary Care Units (CCUs), where the type and number of therapeutic interventions are different to those in the ICU, are even more limited ${ }^{(14-16)}$. Moreover, potential associations between nurses' professional satisfaction and nursing workload have not been adequately addressed to date.

Issues of nursing workload and job satisfaction vary across countries ${ }^{(6-7,10)}$. In Greek health care settings, exploration of nursing workload is also very limited ${ }^{(17-18)}$. Furthermore, although a few studies have explored professional satisfaction among Greek hospital nurses ${ }^{(6,19)}$, these issues have not been addressed among Greek CCU nurses. Therefore, the purpose of the current study was to explore professional satisfaction among Greek CCU nurses and to investigate potential associations between nurses' work satisfaction and nursing workload in the CCU.

\section{METHOD}

\section{DESIGN}

A descriptive correlational study with cross-sectional comparisons was carried out over a 3 year period (from May 2007 to June 2010). The study was conducted in compliance with the required ethical standards (Hospital Ethics Committee approvals were acquired).

\section{SAMPLE AND SETTING}

A random sample of six public Greek Coronary Care Units (CCUs) was selected. Study CCUs were located in three different Greek cities and within tertiary hospitals, four in the Athens Metropolitan area (urban), and two in the periphery (rural: one in Patras, and one in Ioannina). The CCU inclusion criteria were: (a) a capacity of at least five functional beds; (b) number of staff nurses not less than 13 , so that nursing workload is not underestimated due to nursing shortage; (c) no admission of cardiosurgery patients, because the demands of their care exceed those of the usual care provided to CCU patients. Random sampling of CCUs was performed through allocation of random numbers by a computer software program (Excel, Microsoft).

In order to estimate nursing personnel's work satisfaction, the entire nursing staff of the six CCUs (85 nurses) was included in the study, regardless of working experience and educational background.

\section{DATA COLLECTION}

Following administrative approval, nursing workload was measured over a period of 21 weeks in total. More specifically, in five of the selected CCUs, workload data were collected over 20 weeks, (4 weeks per CCU, one week per season of the year, randomly selected). In the 6th CCU, administrative constraints restricted data collection to only 1 week. Patients' records, observation, and information from nursing staff were used as sources of data. Workload measuring instruments were completed every 24 hours around 8am, by the lead researcher, who was not involved in the delivery of care in any of the selected CCUs.

A self-administered anonymous questionnaire was distributed to the nursing personnel of the selected CCUs. The questionnaires were left with the head nurse of each CCU, who was responsible for their distribution. Each questionnaire was accompanied by an introductory letter explaining the purpose of the study and assuring anonymity and confidentiality. After a 4 week-period, the questionnaires were collected by the primary researcher. Return of a completed questionnaire was considered equivalent to the participant's consent to participate in the study.

\section{DATA COLLECTION INSTRUMENTS}

The questionnaire used for the assessment of CCU nurses' professional satisfaction consisted of two sections: (a) a demographic, educational and professional data collection form and (b) the Index of Work Satisfaction (IWS) instrument (developed and revised by Stamps ${ }^{(20)}$ ), adapted to the Greek language in a previous study ${ }^{(6)}$. The IWS tool estimates both the level of professional satisfaction and the perceived importance of the following six job dimensions: pay, professional status, task requirements, interactions, organizational policies and autonomy ${ }^{(20)}$. Furthermore, this scale consists of two parts. Part A assesses the level of importance for each of the aforementioned six job dimensions and ranks the degree of its importance for the professional satisfaction of nurses, with a weighting coefficient factor given to each dimension, referred to by Stamps ${ }^{(20)}$ as component (component weighting coefficient). In more detail, Part A consists of 15-item paired comparisons, where respondents are asked to choose which of the two job components is more important to them in relation to their work satisfaction. Part B of the scale consists of 44 Likert-7 items, and measures the current level of satisfaction for the same six job dimensions. The responses range from 1 ('strongly agree') to 7 ('strongly disagree'). A total single score of the IWS is calculated by multiplying the six component scores derived from Part 
$\mathrm{B}$ by their matching component weighting coefficients from Part A. The resulting weighted component scores are then summed to generate the IWS score and divided by 6 , which reflects the six aforementioned job domains. This score ranges from 0.5 to 39.7 , and represents the Index of Work Satisfaction, including both the importance of the components and the current level of satisfaction.

For the evaluation of nursing workload, a literature review was conducted in order to assess relevant nursing workload scoring systems, and to select the most appropriate. Nursing Activities Score (NAS)(21) and the Comprehensive Nursing Intervention Score (CNIS) ${ }^{(22)}$ were assessed and selected as the most appropriate scales. The Therapeutic Intervention Scoring System-28 (TISS-28) ${ }^{(23)}$ was used as the gold standard. Permissions to use were obtained for each instrument. NAS consists of 23 job items applied for nursing care duties and each item is scored in a range of 1.2 to 32 points. Items 1,4,6,7 and 8 are consisted of $a, b$ and $c$ subcategories. The selection of one subcategory automatically excludes any other item-subcategory. CNIS consists of 8 subscales containing 73 job items. Each item receives 0-3 points from each one of the six aspects of workload that the instrument evaluates: job intensity, muscular exertion, mental stress, special skills, time required and number of nurses required.

Validation of the Greek versions of NAS, CNIS and TISS-28, for the CCU, was performed during a pilot study ${ }^{(18)}$.

\section{STATISTICAL ANALYSIS}

Internal consistency reliability analyses (Cronbach's $\alpha$ ), descriptive statistics (mean $\pm \mathrm{SD}$, frequencies) and parametric correlation analyses were carried out, using appropriate software (Statistical Package for Social Sciences, SPSS, ver.13.0. Chicago, IL). Differences among groups were explored by t-test or ANOVA, as indicated, and correlations between variables were quantified by Pearson's correlation coefficient r. Dependent variables were IWS and its component scores, whilst independent variables were NAS, CNIS and TISS-28 scores, as well as demographic, educational and professional variables. Additionally, stepwise linear regression analysis procedures were conducted to identify the predictive validity of any research variable on the score of the IWS scale.

The alpha level was set at 0.05 and in case of multiple bivariate comparisons, Bonferroni adjustment was applied.

\section{RESULTS}

A total of 811 daily workload reports were obtained from a sample of 311 patients. With regard to work satisfaction questionnaires, the response rate was $77.6 \%(66 / 85)$.

\section{NURSES' DEMOGRAPHIC, EDUCATIONAL AND PROFESSIONAL DATA}

The respondents' mean age was $37.1( \pm 6.5)$ years, they had a mean of $10.6( \pm 7.2)$ total years of nursing experience and $8.4( \pm 8.3)$ years of work experience in the CCU, while $80.3 \%$ of them had a 3-shift around-the-clock schedule and a mean number of $2.9( \pm 0.8)$ working weekends per month. Furthermore, the majority of them were: women $(72.7 \%)$; married (54.5\%); registered nurses (59.1\%); holders of a Technological Institute degree in Nursing (56.1\%); and employees in hospitals located in the Athens metropolitan area (71.2\%). More detailed descriptive data are presented in Table 1.

Table 1 - Frequencies ( $\mathrm{n}^{\circ}$ and \%) of the demographic, educational and professional characteristics of the nursing personnel participated in the study* - Kalamata, Greece, 2010.

\begin{tabular}{|c|c|c|}
\hline Variables & Frequency & Percentage \\
\hline Male & 18 & 27.3 \\
\hline Female & 48 & 72.7 \\
\hline Single & 26 & 39.4 \\
\hline Married & 36 & 54.5 \\
\hline Divorced & 4 & 6.1 \\
\hline Bachelor degree nurses (no MSc) & 12 & 18.1 \\
\hline Associate degree nurses (no MSc) & 37 & 56.1 \\
\hline Diploma degree nursing assistants & 17 & 25.8 \\
\hline MSc degree & 5 & 7.5 \\
\hline $\begin{array}{l}\text { Associate degree nurses holding nursing } \\
\text { specialty diploma }\end{array}$ & 4 & 6.0 \\
\hline Urban Tertiary Hospital (Athens) & 47 & 71.2 \\
\hline Rural Tertiary Hospital (Patra \& loannina) & 19 & 28.8 \\
\hline Full-time working pattern (40 hours/week) & 64 & 97.0 \\
\hline Maternity time working pattern (30 hours/week) & 2 & 3.0 \\
\hline Morning shift & 8 & 12.2 \\
\hline Evening shift & 2 & 3.0 \\
\hline Night shift & 3 & 4.5 \\
\hline Round-the-clock shift & 53 & 80.3 \\
\hline Auxiliary nurse position & 17 & 25.8 \\
\hline Registered Nurse & 39 & 59.1 \\
\hline Nurse in charge & 9 & 13.6 \\
\hline Head nurse & 1 & 1.5 \\
\hline
\end{tabular}

\section{Metric PROPERTIES OF INSTRUMENTS USED}

Cronbach's alpha reliability coefficient for the entire IWS was $\alpha=0.78$. As regards to IWS subscales, reliability coefficients ranged as follows: 0.82 for "Pay", 0.42 for "Professional status", 0.73 for "Interaction", 0.72 for "Task requirements", 0.70 for "Organization policies" and 0.82 for "Autonomy". Cronbach's alpha was estimated as 0.62 , 0.93 and 0.69 respectively for NAS, CNIS and TISS-28. NAS and CNIS measurements as well as NAS/TISS-28 and CNIS/TISS-28 correlated significantly with a strong positive linear relationship $(r \geq 0.90, p<0.001)$ which supports the validity of NAS and CNIS measurements.

\section{DESCRIPTIVE STATISTICS OF NURSES' RESPONSES TO THE IWS INSTRUMENT}

The mean IWS score was $10.7( \pm 2.1)$. The most highly valued component of satisfaction, as reflected in the perceived importance of each item, was "Pay", followed by "Task requirements", "Interaction", "Professional status", "Organizational policies" and "Autonomy". Detailed data of work satisfaction parameters are included in Tables 2 and 3. 
Table 2 - IWS's Part A components' weight coefficients and ranking of their relative importance according to participants' responses (perceived importance of work satisfaction components) - Kalamata, Greece, 2010.

\begin{tabular}{lcc}
\hline IWS's Component & Component weight coefficient - Part A & Ranking of relative importance - Part A \\
\hline Pay & 3.748 & 1 \\
Task requirements & 3.279 & 2 \\
Interaction & 3.199 & 3 \\
Professional Status & 2.882 & 4 \\
Organizational policies & 2.748 & 5 \\
Autonomy & 2.745 & 6 \\
\hline
\end{tabular}

Table 3 - Mean scores of IWS's Part B subscales expressed as average Likert-7 ratings (current level of work satisfaction components) - Kalamata, Greece, 2010.

\begin{tabular}{lcccc}
\hline IWS's component & Mean(SD) & Minimum & Maximum & $\begin{array}{c}\text { Ranking of the degree of current Satisfaction - Part B } \\
\text { (ranking of component mean score) }\end{array}$ \\
\hline Professional Status & $4.6(0.9)$ & 2.7 & 6.6 & 1 \\
Interaction & $4.4(1.0)$ & 2.5 & 7.0 & 2 \\
Autonomy & $3.7(0.9)$ & 1.8 & 5.8 & 3 \\
Organizational policies & $3.0(1.0)$ & 1.9 & 5.6 & 4 \\
Task requirements & $2.9(1.3)$ & 1.0 & 5.7 & 6 \\
Pay & $2.4(1.6)$ & 1.0 & 7.0 & 14.7 \\
Total Index of Work Satisfaction & $10.7(2.1)$ & 7.1 & & \\
\hline
\end{tabular}

\section{GROUP COMPARISONS}

The level of professional satisfaction varied by hospital location ( $\mathrm{p}=0.05)$. Job satisfaction levels appeared higher for total IWS $(\mathrm{p}=0.05)$ and the autonomy component scores $(\mathrm{p}=0.001)$ in rural hospitals. Additionally, the variability of actual levels of job satisfaction appeared to relate to shift work and work position. Autonomy levels were lower for assistant nurses $(\mathrm{p}=0.004)$ and for respondents working the night shift $(\mathrm{p}=0.004)$. In Table 4 , only the independent variables' results that have shown statistically significant differences are presented.

Table 4 - Results from the analysis between the total IWS score and components according to the independent variables - Kalamata, Greece, 2010.

\begin{tabular}{|c|c|c|c|c|c|c|c|c|}
\hline & \multicolumn{6}{|c|}{ IWS Components } & \multirow{2}{*}{\multicolumn{2}{|c|}{ Total IWS }} \\
\hline & \multicolumn{2}{|c|}{ Task requirements } & \multicolumn{2}{|c|}{ Organizational policies } & \multicolumn{2}{|c|}{ Autonomy } & & \\
\hline & Mean(SD) & p & Mean(SD) & $\mathbf{p}$ & Mean(SD) & $\mathbf{p}$ & Mean(SD) & p \\
\hline \multicolumn{9}{|l|}{ Hospital's Location } \\
\hline Rural Tertiary Hospital & $3.3(1.3)$ & 0.079 & $3.1(1)$ & 0.600 & $4.3(0.8)$ & $0.001 *$ & $11.5(2.3)$ & $0.050^{*}$ \\
\hline Urban Tertiary Hospital & $2.7(1.2)$ & & $3(1)$ & & $3.5(0.8)$ & & $10.4(1.9)$ & \\
\hline \multicolumn{9}{|l|}{ Shift } \\
\hline Morning & $3.9(0.9)$ & $0.010^{* *}$ & $4(0.9)$ & $0.005^{* *}$ & 4.4(0.9) & $0.004 * *$ & $12.3(1.8)$ & $0.012^{* *}$ \\
\hline Night & $1.5(0.4)$ & & $2(0.2)$ & & $2.5(0.5)$ & & 8.5(0.5) & \\
\hline Round-the-clock & $2.8(1.2)$ & & $2.9(1)$ & & $3.7(0.8)$ & & $10.6(2)$ & \\
\hline \multicolumn{9}{|l|}{ Ranking } \\
\hline Nurse assistant & $2.6(1.2)$ & 0.360 & $2.9(1)$ & 0.355 & $3.2(0.9)$ & $0.004 * *$ & $10.2(2)$ & 0.291 \\
\hline Registered nurse & $2.9(1.3)$ & & $3(1.1)$ & & $3.8(0.8)$ & & $10.7(2.1)$ & \\
\hline Nurse in charge/Head nurse & $3.3(1.1)$ & & $3.5(1)$ & & $4.3(0.8)$ & & $11.5(1.9)$ & \\
\hline
\end{tabular}

\section{BIVARIABLE ASSOCIATIONS AMONG NURSING WORKLOAD AND PROFESSIONAL SATISFACTION COMPONENTS}

Significant associations were detected between professional satisfaction components and nursing workload scores. More specifically, NAS, CNIS and TISS-28 total scores were negatively correlated, with a low to moderate linear relationship, with the IWS total score as well as with professional satisfaction components: autonomy $(\mathrm{p}<0.006)$, professional status $(\mathrm{p} \leq 0.01)$, interaction $(\mathrm{p} \leq 0.01)$ and task requirements $(p \leq 0.04)$. These results are presented in Table 5 . 
Table 5 - Correlations* between professional satisfaction components and nursing workload scores - Kalamata, Greece, 2010.

\begin{tabular}{|c|c|c|c|c|c|c|}
\hline \multirow{3}{*}{ Professional Satisfaction Components } & \multicolumn{6}{|c|}{ Nursing Workload } \\
\hline & \multicolumn{2}{|c|}{ NAS score } & \multicolumn{2}{|c|}{ CNIS score } & \multicolumn{2}{|c|}{ TISS-28 score } \\
\hline & $\mathbf{r}$ & $\mathbf{p}$ & $\mathbf{r}$ & $\mathbf{p}$ & $\mathbf{r}$ & $\mathbf{P}$ \\
\hline Pay & 0.03 & 0.798 & -0.08 & 0.515 & -0.04 & 0.778 \\
\hline Professional status & -0.34 & 0.005 & -0.31 & 0.011 & -0.31 & 0.011 \\
\hline Interaction & -0.34 & 0.006 & -0.31 & 0.010 & -0.33 & 0.007 \\
\hline Task requirements & -0.25 & 0.040 & -0.37 & 0.003 & -0.33 & 0.007 \\
\hline Autonomy & -0.43 & $<0.001$ & -0.45 & $<0.001$ & -0.43 & $<0.001$ \\
\hline Total Index of Work Satisfaction & -0.34 & 0.006 & -0.44 & $<0.001$ & -0.39 & 0.001 \\
\hline
\end{tabular}

*Pearson's test

\section{PREDICTORS OF NURSES' PROFESSIONAL SATISFACTION}

Multiple regression analysis revealed that only working shift pattern could be used as a possible predictor of CCU nurses' IWS score. Nurses working on day shifts demonstrated a total score which was higher by 3.77 points to the one of nurses working on night shifts $(\beta=3.77, \mathrm{SE}=1.30, \mathrm{P}=0.005)$.

\section{DISCUSSION}

This study describes the first application of the Greek versions of the Nursing Activities Score (NAS), the Comprehensive Nursing Intervention Score (CNIS), the Therapeutic Intervention Scoring System-28 (TISS-28) and Stamps Index of Work Satisfaction (IWS), to assess nursing workload and correlation with nurses' job satisfaction in Coronary Care units in Greece. The main findings of this study included: a) low to moderate levels of job satisfaction, according to the cut-off points provided by Stamps ${ }^{(20)}$ b) significant correlations between professional satisfaction components and nursing workload scores, although nursing workload scores were not found as possible predictors of $\mathrm{CCU}$ nurses' work satisfaction c) working shift pattern as a possible predictor of CCU nurses' professional satisfaction.

Despite satisfactory reliability of the IWS, CNIS, and TISS-28, low reliability results for the IWS subscale "Professional Status", and moderate for the NAS, were detected. Regarding IWS, Stamps ${ }^{(20)}$ has already mentioned that some items (2 and 9) of the "Professional Status" subscale lead to low reliabilities and suggested their exclusion. Since the overall reliability for the total IWS was above satisfactory levels, a decision was made not to eliminate low correlation items in the present study. Additionally, the moderate reliability for NAS could be attributed to the nature and scope of this scale. Cronbach's $\alpha$ reflects an instrument's homogeneity. Homogeneity testing examines the extent to which all the items in the instrument consistently measure the major elements/parameters (construct) of a phenomenon (concept). It determines the agreement of selecting items in the same way. NAS includes items $1,4,6,7$ and 8 that consist of a, b and $\mathrm{c}$ subcategories. The selection of one subcategory automatically excludes any other, which may diminish Cronbach's $\alpha$ value, because items-subcategories that approach the same parameter can't be chosen together. Taking all the above into consideration, the internal consistency reliability for NAS, as measured in the current study, was considered satisfactory.
In the present study, the average value for total IWS was 10.7, indicating rather low overall satisfaction among Greek Coronary Care Unit nurses. This finding is in accordance with a previous report of low to moderate professional satisfaction levels among Greek ICU nurses ${ }^{(6)}$. The highest levels of work satisfaction components (Part B) were observed in relation to the "Professional status" followed by "Interaction" and "Autonomy" components, whereas the lowest levels were in relation to "Pay" and "Task requirements" subscales. Additionally, "Pay" and "Task requirements" received high ranking in terms of importance (Part A), while "Autonomy" received the lowest perceived importance of work satisfaction components. According to Stamps ${ }^{(20)}$, discrepancies between the level of current satisfaction of each work component in Part B (i.e low score) and the degree of importance of the same job component in Part A (i.e high score) may implicate nurse managers' interventions, since such work components seem to influence negatively employees'work satisfaction. Consequently, it seems that the main factors influencing negatively the level of professional satisfaction among CCU nursing personnel in the present study were Pay and Tasks. These results are in line with findings among Italian nurses, which suggest the main sources of professional satisfaction to be "Interactions between nurses", "Professional status", and "Autonomy", whilst "Pay" and "Job requirements" were the least satisfying work components ${ }^{(24)}$. Moreover, other researchers have reported that pay, workplace circumstances, and increased workload are all important in determining professional dissatisfaction and quitting rates among nurses ${ }^{(25)}$.

The "Autonomy" component scores varied significantly by nurses' work position. Nurse assistants showed the lowest autonomy satisfaction level. This result is supported by other findings demonstrating that the perceived importance and actual satisfaction from the IWS six job components varied by position among nursing personnel in Hong Kong ${ }^{(26)}$. Hospital location and working shifts were also associated with IWS components, as well as with the overall IWS score. Nurses working in a rural tertiary hospital reported higher autonomy and IWS scores than those employed in Athens hospitals. These results are in contrast with the findings of a study ${ }^{(25)}$ reporting that job satisfaction among NHS (National Health Service in England) hospital nurses was not affected by either employer size or location, but nurses working in General District Hospitals reported lower job 
satisfaction than other NHS employers. According to the above, questions emerge about organizational policies in Greek urban hospitals which need further investigation.

Furthermore, Greek CCU nurses working the day shift reported higher levels of job satisfaction as well as autonomy, tasks and organizational satisfaction than nurses working round-the-clock, or the night shift. This finding could be explained by the results, which show that the more stable the work schedule, the less work-related stress, the lower anticipated turnover and the higher group cohesion are related with higher work satisfaction ${ }^{(27)}$. Other data show that the 'quality' of the work environment of nurses is important in explaining variations in job satisfaction. In particular: a) working a shift pattern which is not to the employee's liking, b) not being treated fairly as regards to one's duties, and c) working overtime (often unpaid) significantly reduce job satisfaction ${ }^{(25)}$. Conversely being at a workplace which encourages personal initiatives, participating in post-basic training, and having additional reimbursement over one's working hours significantly increases job satisfaction ${ }^{(25)}$.

In the present study, higher overall levels of nursing workload were associated with lower CCU nurses' job satisfaction, although work load scores could not predict IWS scores, probably due to statistical power limitations stemming from sample size. More specifically, negative correlations were detected not only with the overall IWS score, but also with Status, Interaction, Tasks and Autonomy sub-scores. Although literature reports on workload and nurse job satisfaction are limited, our results are in accordance with the study that demonstrated a correlation between high workload and poor job satisfaction, followed by an intention to quit, among registered nurses in Nordic hospitals ${ }^{(28)}$. It appears that the current worldwide nursing shortage contributes to heavier workload, which leads to a more stressful job environment with more tasks to accomplish (under time pressure) and conflicts among healthcare professionals. Greater workload also means more routine nursing work that leads to lower autonomy levels, burnout and intention to quit ${ }^{(29)}$.

\section{StRenGthS AND LIMITATIONS OF THE STUDY}

The random CCU sampling was one of the study's strengths and although only six hospitals were included, the results can be generalized to the rest of Greece because organizational policies are more or less similar and imposed by the Greek Health Ministry throughout the country. The study's limitations are related to the national sample and to the Cronbach's alpha values that were somewhat moderate for the NAS and low for the IWS "Professional Status" subscale. Furthermore, statistical power limitations for multiple regression analysis models should be noted, which could have resulted in the relatively poor prediction of high IWS scores by factors other than the work shift patterns.

\section{CONCLUSION}

Greek CCU nurses demonstrate rather low to moderate levels of satisfaction derived from their profession. The findings reported in this study imply interactions between nurses' professional satisfaction, and nursing workload, pay, shift work, work's location (rural or urban) and position held. Attempts towards a higher level of nurses' professional satisfaction should include better working conditions, fewer shifts and better paid work. Future investigation of other factors interfering with job satisfaction, such as burnout or morale, in relation to nursing workload, could provide useful insights into professional dissatisfaction among nursing personnel.

\section{RESUMO}

Objetivo: Explorar as potenciais associações entre a carga laboral e a satisfação profissional das equipes de enfermagem nas Unidades de Cuidados Coronarianos Gregas. Método: Estudo transversal com 66 membros das equipes que desenvolvem suas atividades em seis diferentes unidades, selecionadas aleatoriamente. A satisfação no trabalho foi avaliada pelo Index of Work Satisfaction (IWS) e a carga laboral pelo Nursing Activities Score (NAS), Comprehensive Nursing Antervention Score(CNIS) e Therapeutic Intervention Scoring System-28 (TISS-28). Resultados: A taxa de resposta foi de $77.6 \%$. A confiabilidade do IWS foi de $\alpha=0.78$ e a média 10.7 ( \pm 2.1 ,intervalo:0.5-39.7). O componente de satisfação mais valorizado foi "Remuneração", seguido por "Requisitos da Tarefa", "Interação", "Status Profissional”, "Políticas Organizacionais" "Autonomia”. NAS, CNIS e TISS-28 foram correlacionados negativamente $(\mathrm{p} \leq 0.04)$ com os seguintes componentes de trabalho: "Autonomia", "Status Profissional" "Interação" e "Requisitos da Tarefa". O trabalho no turno noturno definiu independentemente o índice de IWS. Conclusão: Os resultados mostraram níveis baixos de satisfação no trabalho, que estão relacionados com a carga laboral e influenciados pelos turnos rotativos.

\section{DESCRITORES}

Equipe de Enfermagem; Unidade de Cuidados Coronarianos; Carga de Trabalho; Satisfação no Emprego; Trabalho em Turnos; Autonomia Profissional.

\section{RESUMEN}

Objetivo: Explorar las asociaciones potenciales entre la carga laboral y la satisfacción profesional del personal de enfermería en las Unidades Griegas de Cuidados Coronarios. Método: Estudio transversal en 66 miembros das equipes, seleccionados al azar, que están empleados en 6 diferentes unidad griegas. La satisfacción en el trabajo se evaluó por el Index of Work satisfaction (IWS) y la carga laboral pelo Nursing Activities Score (NAS), Comprehensive Nursing Intervention Score (CNIS) y Therapeutic Intervention Scoring System-28 (TISS-28). Resultados: La tasa de respuesta fue del 77,6\%. La fiabilidad del IWS fue de $\alpha=0,78$ y la media 10,7( $\pm 2,1$, rango de escala:0,5-39,7). El componente de la satisfacción más valorado fue "Salario", seguido de "Requisitos de la tarea", "Interacción", "Estatus Profesional", "Políticas Organizacionales" y "Autonomía". NAS, CNIS y TISS-28 se correlacionaron negativamente ( $\leq 0.04)$ con los siguientes componentes de trabajo:"Autonomía”, "Estatus Profesional”,"Interacción” y "Requisitos de la tarea”. El trabajo en el turno nocturno definió independientemente el índice de IWS. Conclusión: Los resultados muestran bajos niveles de satisfacción en el trabajo del personal de enfermería que están relacionados con la carga laboral e influenciados por los turnos rotativos.

Grupo de Enfermería; Unidad de Cuidados Coronarios; Carga de Trabajo; Satisfacción en el Trabajo; Trabajo por Turnos; Autonomía Profesional. 


\section{REFERENCES}

1. Mottaz CJ. Work satisfaction among hospital nurses. Hosp Health Serv Adm. 1988;33(1):57-74.

2. Aiken LH, Clarke SP, Sloane DM, Sochalski J, Silber JH. Hospital nurse staffing and patient mortality, nurse burnout and job dissatisfaction. JAMA. 2002;288(16):1987-93.

3. Cortese CG. Predictors of intention to leave the nursing profession in two Italian hospitals. Assist Inferm Ric. 2013;32(1):20-7.

4. Karanikola MN, Papathanassoglou ED, Kalafati M, Stathopoulou H. Exploration of the association between professional interactions and emotional distress of intensive care unit nursing personnel. Dimens Crit Care Nurs. 2012;31(1):37-45.

5. Lai HL, Lin YP, Chang HK, Wang SC, Liu YL, Lee HC, Peng TC, Chang FM. Intensive care unit staff nurses: predicting factors for career decisions. J Clin Nurs. 2008;17(14):1886-96.

6. Karanikola M, Papathanassoglou EDE, Giannakopoulou M, Koutroubas A. Pilot exploration of the association between self-esteem and professional satisfaction in Hellenic Hospital Nurses. J Nurs Manag. 2007;15(1):78-90.

7. Karanikola MN, Albarran JW, Drigo E, Giannakopoulou M, Kalafati M, Mpouzika M, et al. Moral distress, autonomy and nurse-physician collaboration among intensive care unit nurses in Italy. J Nurs Manag. 2014;22(4):472-84.

8. Cafaro G, Sansoni J. Job satisfaction: a comparative study between public and private practice. Prof Inferm. 2010;63(2):67-76.

9. Nogueira LS, Koike KM, Sardinha DS, Padilha KG, Sousa RM. Nursing workload in public and private intensive care units. Rev Bras Ter Intensiva. 2013;25(3):225-32.

10. Stafseth SK, Solms D, Bredal IS. The characterisation of workloads and nursing staff allocation in intensive care units: a descriptive study using the Nursing Activities Score for the first time in Norway. Intensive Crit Care Nurs. 2011;27(5):290-4

11. Padilha KG, de Sousa RM, Garcia PC, Bento ST, Finardi EM, Hatarashi RH. Nursing workload and staff allocation in an intensive care unit: a pilot study according to Nursing Activities Score (NAS). Intensive Crit Care Nurs. 2010;26(2):108-13.

12. Carayon P, Gürses AP. A human factors engineering conceptual framework of nursing workload and patient safety in intensive care units. Intensive Crit Care Nurs. 2005;21(5):284-301.

13. Carayon P, Alvarado CJ. Systems Engineering Initiative for Patient Safety.Workload and patient safety among critical care nurses. Crit Care Nurs Clin North Am. 2007;19(2):121-9.

14. Timmins F. Conceptual models used by nurses working in coronary care units--a discussion paper. Eur J Cardiovasc Nurs. 2006;5(4):253-7.

15. Amoroso G, Sarti M, Bellucci R, Puma FL, D'Alessandro S, Limbruno U, et al. Clinical and procedural predictors of nurse workload during and after invasive coronary procedures: the potential benefit of a systematic radial access. Eur J Cardiovasc Nurs. 2005;4(3):234-41.

16. Whalen KL. Level of nursing care required by the unstable angina patient. Crit Care Med. 1990;18(5):505-8.

17. Giakoumidakis K, Baltopoulos Gl, Charitos C, Patelarou E, Fotos NV, Brokalaki-Pananoudaki H. Risk factors for increased in-hospital mortality: a cohort study among cardiac surgery patients. Eur J Cardiovasc Nurs. 2012;11(1):23-33.

18. Gouzou M, Papathanassoglou EDE, Lemonidou C, Dimoni C, Kletsiou E, Giannakopoulou M. Pilot validation of the nursing scoring systems NAS and CNIS in Hellenic coronary care units [abstract]. Eur J Cardiovasc Nurs. 2009;8 Supl 1:S3.

19. Kapella M, Minettou E, Ziga S. Measuring nurses'satisfaction from their job. Nosileftiki. 2002;2:191-6.

20. Stamps LP. Nurses and work satisfaction: an index for measurement. Chicago, IL: Health Administration Press; 1997.

21. Reis Miranda D, Nap R, Angelique MA, Schaufeli W, lapichino G. Nursing activities score. Crit Care Med. 2003;31(2):374-82.

22. Yamase H. Development of a comprehensive scoring system to measure multifaceted nursing workloads in ICU. Nurs Health Sci. 2003;5(4):299-308.

23. Miranda DR, de Rijk A, Schaufeli W. Simplified Therapeutic Intervention Scoring System: The TISS-28 items--results from a multicenter study. Crit Care Med. 1996;24(1):64-73.

24. Cortese CG. Predictors of intention to leave the nursing profession in two Italian hospitals. Assist Inferm Ric. 2013;32(1):20-7.

25. Shields MA, Ward M. Improving nurse retention in the National Health Service in England: the impact of job satisfaction on intentions to quit. J Health Econ. 2001;20(5):677-701.

26. Cheung K, Ching SS. Job satisfaction among nursing personnel in Hong Kong: a questionnaire survey. J Nurs Manag. 2014;22(5):664-75.

27. Shader K, Broome ME, Broome CD, West ME, Nash M. Factors influencing satisfaction and anticipated turnover for nurses in an academic medical center. J Nurs Adm. 2001;31(4):210-6.

28. Lindqvist R, Smeds Alenius L, Runesdotter S, Ensio A, JylhäV, Kinnunen J, et al. Organization of nursing care in three Nordic countries: relationships between nurses' workload, level of involvement in direct patient care, job satisfaction, and intention to leave. BMC Nurs. 2014;13:27.

29. Tummers GE, van Merode GG, Landeweerd JA. The diversity of work: differences, similarities and relationships concerning characteristics of the organisation, the work and psychological work reactions in intensive care and non-intensive care nursing. Int J Nurs Stud. 2002;39(8):841-55. 